\title{
The Role of Some Antioxidants in Diabetes Mellitus Induced in Rats
}

\author{
Nagy S. Tawfek ${ }^{*}$, Mahmoud Abdel-Aziz Elrehany ${ }^{* *}$, and Hanaa Fawzy Hassan ${ }^{*}$ \\ Department of Zoology, Faculty of Science* and Department of Biochemistry, \\ Faculty of Medicine ${ }^{* *}$, El-Minia University, El-Minia, Egypt
}

\begin{abstract}
The aim of the present study was to examine the involvement of oxidative stress in the progression of pancreatic $\beta$-cell dysfunction in type 1 diabetes and to evaluate the potential usefulness of some antioxidants supplementation in the treatment of type 1 diabetes. The severity of diabetes in the different groups has been studied in relation to the level of cytokines released during the oxidative stress. The present study was achieved using 24 male Sprague Dawley albino rats. Rats were divided into three groups: normal control rats, diabetic control rats, and diabetic rats received mixture of antioxidants. A mixture of antioxidants [N-acetyl-cysteine (NAC), alpha-lipoic acid (LA), vitamin E and vitamin C] was orally administered daily to cyclophosphamideinduced diabetic rats for a period of two months. The results revealed that diabetic rats had significant increase in tumor necrosis factor- $\alpha$ (TNF- $\alpha)$ concentration and transcription nuclear factor-kappa beta $(N F-\kappa \beta)$ concentration, as compared to normal control rats. After treatment of diabetic rats with the antioxidants for two months, tumor necrosis factor- $\alpha(T N F-\alpha)$ and nuclear factor-kappa beta (NF- $\kappa \beta)$ concentrations showed a highly significant decrease $(p<0.001)$ when compared with the diabetic control group. Histological analysis of the pancreas revealed that the antioxidants treatment preserved the normal morphology of Islets of pancreas, and $\beta$ cell mass when compared with diabetic rats. The combination of these antioxidants was more effective in suppression of apoptosis which was associated with the development of type 1 diabetes. Immunohistochemical analysis indicated that antioxidants protect $\beta$-cell from cytokine induced dysfunction and death through inhibition of specific nuclear factor $-\kappa \beta$ activity which was more visible in the nuclei of Islet cells in diabetic rats than antioxidants-treated rats. On the basis of the present results it could be concluded that [N-acetyl-cysteine (NAC), alpha-lipoic acid (LA), vitamin $E$ and vitamin $C]$ restored the activities of the above parameters in different ways, depending on special mechanism in each one. Supplementation of antioxidants at once after diagnosis of diabetes may delay the complications of diabetes. This finding suggests a potential usefulness of antioxidants for treating diabetes and provides further support for the implication of oxidative stress in $\beta$-cell dysfunction in diabetes by providing protection against hyperglycemia.
\end{abstract}

\section{INTRODUCTION}

Type 1 diabetes mellitus is an autoimmune disease in which mononuclear cells of the immune system (macrophages and lymphocytes) infiltrate the pancreatic islets of Langerhans (insulitis), 
leading to selective destruction of the islets $\beta$-cells and to insulin dependent diabetes mellitus. Apoptosis has been identified as a mechanism of pancreatic islets $\beta$-cell death in autoimmune diabetes ${ }^{(\mathbf{1})}$.

Pancreatic $\beta$-cell apoptosis is known to participate in the $\beta$-cell destruction process that occurs in diabetes. It has been described that high glucose level induces a hyperfunctional status which could provoke apoptosis. This phenomenon is known as glucotoxicity and has been proposed that it can play a role in type 1 diabetes mellitus pathogenesis $^{(2)}$.

Proinflammatory cytokines such as interleukin (IL)-1 $\beta$, interferon (IFN)- $\gamma$, and tumor necrosis factor- $\alpha$ (TNF- $\alpha$ ) are critically involved in the pathogenesis of type 1 diabetes. For instance, it has been shown that IL-1 $\beta$, IFN- $\gamma$, and TNF- $\alpha$ synergistically impair $\beta$-cell function and cause $\beta$-cell death when incubated with isolated rat islets. Free radicals, particularly reactive oxygen species (ROS), have been implicated in the cytokine mediated islet cell injury, mostly on the basis of the protective effect of antioxidants in different models of type 1 diabetes. ROS generation, evidenced by the formation of lipid peroxidation products, is believed to be the ultimate cause of cytokinemediated death of $\beta$-cells ${ }^{(3)}$.

Nuclear transcription factor-к $\beta$ $(\mathrm{NF}-\kappa \beta)$ is a transcription factor that can be activated by a variety of stresses such as oxidants, viruses, and proinflammatory cytokines. NF-к $\beta$ is usually stored in the cytosol in its inactive form bound to the inhibitory unit iк $\beta$. Activation of NF-к $\beta$ in response to extracellular stimuli involves the release of ік $\beta$, resulting in a rapid translocation of NF-K $\beta$ to the nucleus. ROS appear to be a key factor in initiating NF- $\kappa \beta$ activation. Once activated, NF-к $\beta$ binds to nuclear DNA and modulates the expression of several genes for adhesion molecules and up-regulates the production of various proinflammatory cytokines such as IL-2, IL-6, tumor necrosis factor- $\alpha$, and inducible nitric oxide synthase ${ }^{(4)}$.

Animal and human studies and in vitro experiments suggest a role for oxidative stress in the pathophysiology of diabetic complications. High glucose concentration is known to activate a number of enzymatic and nonenzymatic pathways of glucose metabolism that are implicated in ROS production. The resulting increased production of ROS interact with several cellular targets and results in tissue injury ${ }^{(5)}$.

Inactivation and removal of reactive oxygen species depend on reactions involving the antioxidative defense system. The capacity is determined by a dynamic interaction between individual components. Central to this defense are the antioxidants of the blood which include vitamins E, C, $\alpha$-lipoic acid, $\mathrm{N}$-acetyl-cysteine, reduced glutathione (GSH), and several antioxidant enzymes as glutathione peroxidase $(\mathrm{Gpx})^{(6)}$.

The present study was carried out to evaluate the potential usefulness of antioxidants [N-acetyl-cysteine (NAC), alpha-lipoic acid (LA), vitamin $\mathrm{E}$ and vitamin $\mathrm{C}]$ supplementation in the treatment of 
type 1 diabetes. The severity of diabetes in the different groups was studied in relation to the level of cytokines released during the oxidative stress.

\section{MATERIALS \& METHODS}

\section{Experimental animals:}

Twenty four male Sprague Dawely rats, weighing 150-200g were housed in a well ventilated room for 2 weeks before carrying out the experiment.

\section{Induction of diabetes method:}

Diabetes was induced by a double intraperitoneal injection of (100 mg / $\mathrm{kg}$ body weight) of cyclophosphamide (CY) (sigma chemical company) for two successive days according to the method of Apostolou et al. (7). Cyclophosphamide was dissolved in $0.1 \mathrm{M}$ phosphate buffer solution (PBS, $\mathrm{pH}=7.4)$. Cyclophosphamide injected animals exhibited hyperglycemia within $24 \mathrm{~h}$ after injection. Diabetes was confirmed by measuring the fasting blood glucose level, and 200$250 \mathrm{mg} / \mathrm{dl}$ were considered to be mild diabetes and were used in the present experiment.

\section{Experimental design:}

After induction of diabetes the rats were divided into three groups of eight animals as follows:

Group 1: Normal control rats given daily distilled water $(1 \mathrm{ml} / 100 \mathrm{~g}$ body weight) for two months.

Group 2: Diabetic control rats given daily distilled water $(1 \mathrm{ml} / 100 \mathrm{~g}$ body weight) for two months.

Group 3: Diabetic rats given daily a mixture of the following antioxidants: NAC solution $(500 \mathrm{mg} / \mathrm{kg}$ body weight $)^{(8)}$, LA solution (30 mg / kg body weight) ${ }^{(9)}$, Vitamin E (100 IU/kg body weight $)^{(9)}$ and Vitamin C (1 g / $\mathrm{kg}$ body weight $)^{(\mathbf{9})}$. This mixture was administered daily using a stainlesssteal stomach tube for a period of two months, then, the body weight and fasting blood glucose of the animals were again determined.

Collection of blood and tissue samples:

After two months of treatment with antioxidants, the rats were fasted overnight and sacrificed by cervical decapitation. Blood samples were immediately collected; plasma and serum have been separated by centrifugation of blood for 10 minutes at $3000 \mathrm{rpm}$. The plasma was separated for measuring the fasting blood glucose level and the serum was separated for measuring the concentration of tumor necrosis factor- $\alpha$ (TNF- $\alpha)$ and nuclear factor$\kappa \beta$ (NF-к $\beta)$. After animal dissection, the pancreas was obtained and stored in $30 \%$ formalin solution for histological and immunohistochemical studies.

Biochemical analysis:

Glucose was determined spectrophotometrically according to GOD-PAP method of Barham and Trinder ${ }^{(10)}$ using Human diagnostic Kits.

TNF- $\alpha$ was measured using ELISA (enzyme immunoassay kit, Biosource International, Inc.) according to the method of New et al. $^{(11)}$.

Nuclear transcription factor- $\kappa \beta$ (NF-к $\beta$ ) was measured using ELISA Kit (Oxford Biomedical Research, Inc.) according to the method of Davis and Sarkar ${ }^{(12)}$. 


\section{Histopathological examination:}

Pancreatic tissue samples were fixed in $30 \%$ formalin solution followed by dehydration in ascending grades of alcohols (50-100\%). Afterwards, the samples were cleared in xylene, and then impregnated in three successive changes of soft paraffin at $50^{\circ} \mathrm{C}$ and embedded in paraffin wax to obtain solid blocks. Later on, transverse serial sections were done at the thickness of 5 micrometer by rotatory microtome and then sections mounted on DPXcovered glass slides. Subsequently, the slides were stained with hematoxylin and eosin (H\&E) according to the method of Harris ${ }^{\text {(13) }}$. Sections were washed in water, dehydrated in alcohol, cleared in xylene and mounted with DPX. Stained sections were examined and photographed by using light microscope.

Immunohistochemical examination:

The de-waxed paraffin sections were washed three times with PBS for 1-2 minutes, and then put in $2 \%$ horse serum, $0.5 \%$ Triton $\mathrm{X}-100$, and $0.02 \%$ $\mathrm{NaN} 3$ in PBS for 20 minutes. Fixed cells were then subsequentially incubated with anti-insulin $\mathrm{Ab}$ (Biogenex $)^{(\mathbf{1 4})}$, biotinylated antimouse IgG (MP Biomedicals), and streptavidin fluorescein isothiocyanate (Biogenex $)^{(\mathbf{1 5})}$ for 1 hour. Stained cells were washed three times with PBS for 1-2 minutes, and then mounted with glycerol gelly. Stained cells were examined by using fluorescent microscope.

\section{Statistical analysis:}

SPSS for windows evaluation version 15.0 was used for all statistical analysis. All the results were expressed as mean \pm standard error by using student's unpaired ttest. The statistical differences between the groups involved in the studies were assessed by one-way analysis of variance (ANOVA) to analyze specific difference between means. The experimental findings were considered highly statistically significant if $\mathrm{P}<0.001$.

\section{RESULTS}

\section{Biochemical results:}

Table (1) and Figure (1-3) showed a highly significant increase $(\mathrm{P}<0.001)$ in fasting plasma glucose level, TNF- $\alpha$ and NF- $\beta \beta$ concentration of diabetic control group when compared with the normal control group. After treatment of the diabetic rats with the antioxidants for two months, fasting plasma glucose level, TNF- $\alpha$ and NF- $\beta$ concentration showed a highly significant decrease $(\mathrm{p}<0.001)$ when compared with the diabetic control group.

\section{Histopathological results:}

Control pancreatic tissue: $H$ \& E paraffin sections of control pancreatic tissue revealed scattered islets of Langerhans embedded among the pancreatic acini. Islets of Langerhans cells are made up of clusters of epithelial cells separated by fenestrated capillaries. Normal morphology of islets of Langerhans without lymphocyte infiltrations (insulitis) is present (figure 4).

Pancreatic tissue was immunostained with anti-insulin antibody as a primary antibody and visualized with anti- mouse $\operatorname{IgG}$ as a secondary antibody. 
Immunofluorescence staining showed $\beta$-cells in pancreatic islets and the p65 subunit of the transcription factor NF-к $\beta$ complex was in the cytoplasm of $\beta$-cells as a bright green color. No nuclear translocation of transcription factor NF-к $\beta$ was observed into the nucleus (figure 5).

Diabetic pancreatic tissue after two month of induction of diabetes: $\mathrm{H}$ \& E paraffin sections of diabetic pancreatic tissue show prominent destruction of islets epithelial cells, seen as disorganized and dyshesive cells of variable size having evident intercellular spaces and large dense hyperchromic nuclei, concomitant infiltration of lymphocytes (insulitis) within and around the islets. Prominent apoptosis are seen (figure 4).

Immunofluorescence staining showed activation of transcription factor NF-к $\beta$ and nuclear translocation of the p65 subunit from cytosol to nuclei which become visible as a bright green spots. Apoptotic cells appeared as distinct rounded cells with up normal bright green nuclei, due to nuclear condensation/ fragmentation of staining (figure 5).

Diabetic pancreatic tissue receiving antioxidants after two month of induction of diabetes: Islets of Langerhans show relative restoration of the epithelial cells cohesiveness with minimal intercellular spaces. Some islets show normal nuclear and cytoplasmic configuration of the epithelial cells with few foci of wide intercellular spaces. Marked reduction in apoptotic cells and the amount of infiltrating lymphocytes, when compared with diabetic tissue (figure 4).

Immunofluorescence staining showed inhibition of transcription factor NF-к $\beta$ activation is observed and inhibition of nuclear translocation of the p65 subunit of transcription factor NF-к $\beta$ into nuclei is seen (figure 5).

Table (1): The effect of antioxidants administration on different metabolic parameters

\begin{tabular}{|c|c|c|c|}
\hline Groups & Normal control & Diabetic control & $\begin{array}{c}\text { Diabetic treated } \\
\text { with antioxidants }\end{array}$ \\
\hline $\begin{array}{c}\text { Fasting plasma glucose } \\
\text { level (mg/dl) }\end{array}$ & $130.03 \pm 10.40$ & $269.66^{*} \pm 17.15$ & $138.23^{* *} \pm 10.56$ \\
\hline $\begin{array}{c}\text { TNF- } \boldsymbol{\alpha} \text { concentration } \\
\text { (pg / mL) }\end{array}$ & $58.61 \pm 1.59$ & $94.36^{*} \pm 6.03$ & $71.65^{* *} \pm 1.42$ \\
\hline $\begin{array}{c}\text { NF-KB concentration }(\mathbf{p g} \\
\text { / } \mathbf{m L})\end{array}$ & $100.05 \pm 3.66$ & $284.27^{*} \pm 28.10$ & $141.38^{* *} \pm 12.77$ \\
\hline
\end{tabular}

Values are expressed as means $\pm S E$

* and **: Highly significant $(P<0.001)$.

Comparison was made in each parameter between the diabetic control group and the normal control group (*), and between the diabetic treated with antioxidants group and the diabetic control group (**) 


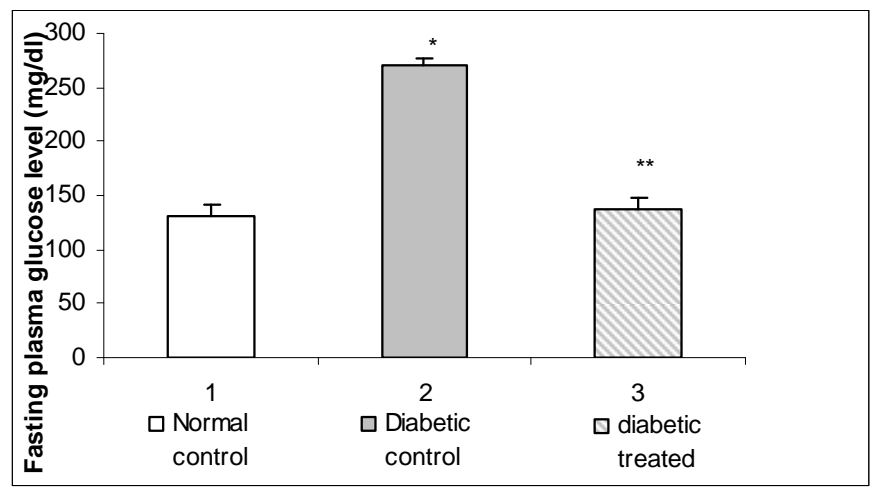

Figure (1): Effects of antioxidants administration on fasting plasma glucose level $(\mathrm{mg} / \mathrm{dl})$ in normal, diabetic and diabetic treated rats after two months.

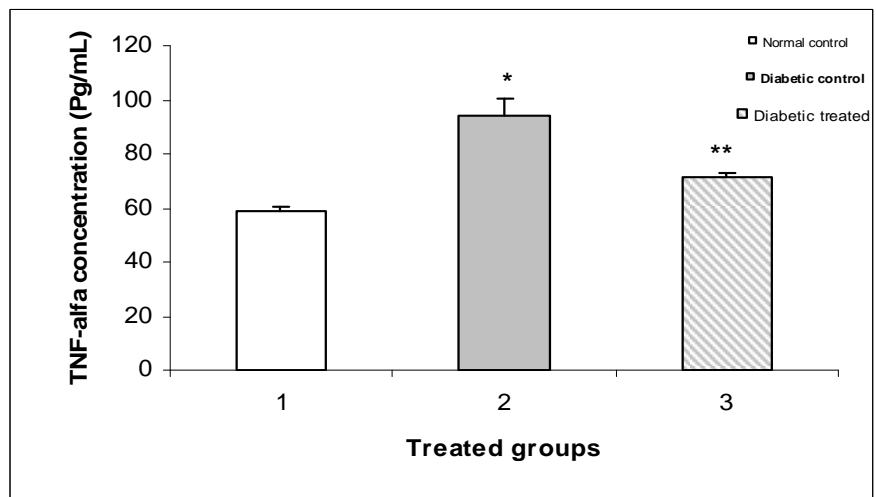

Figure (2): Effects of antioxidants administration on concentration of TNF- $\alpha$ (pg/ml) in normal, diabetic and diabetic treated rats after two months

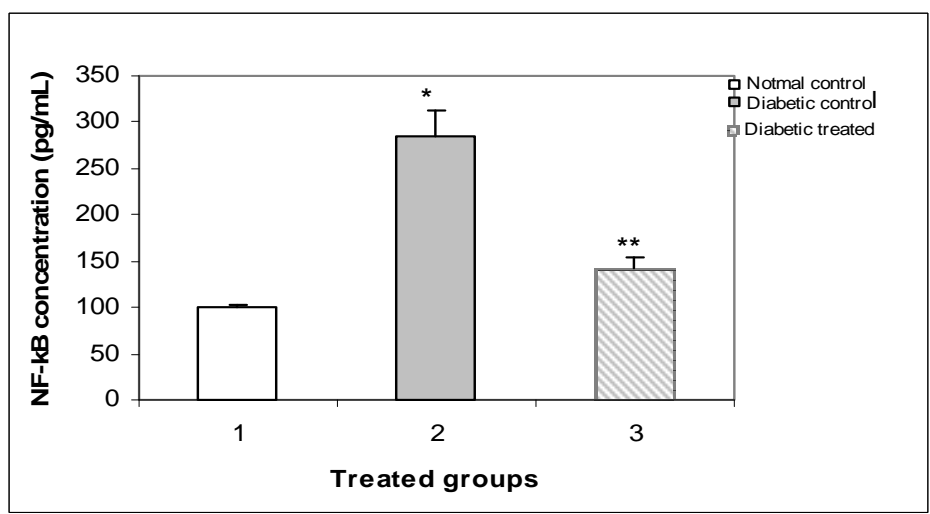

Figure (3): Effects of antioxidants administration on concentration of $\mathrm{NF}-\kappa \beta(\mathrm{pg} / \mathrm{ml})$ in normal, diabetic and diabetic 

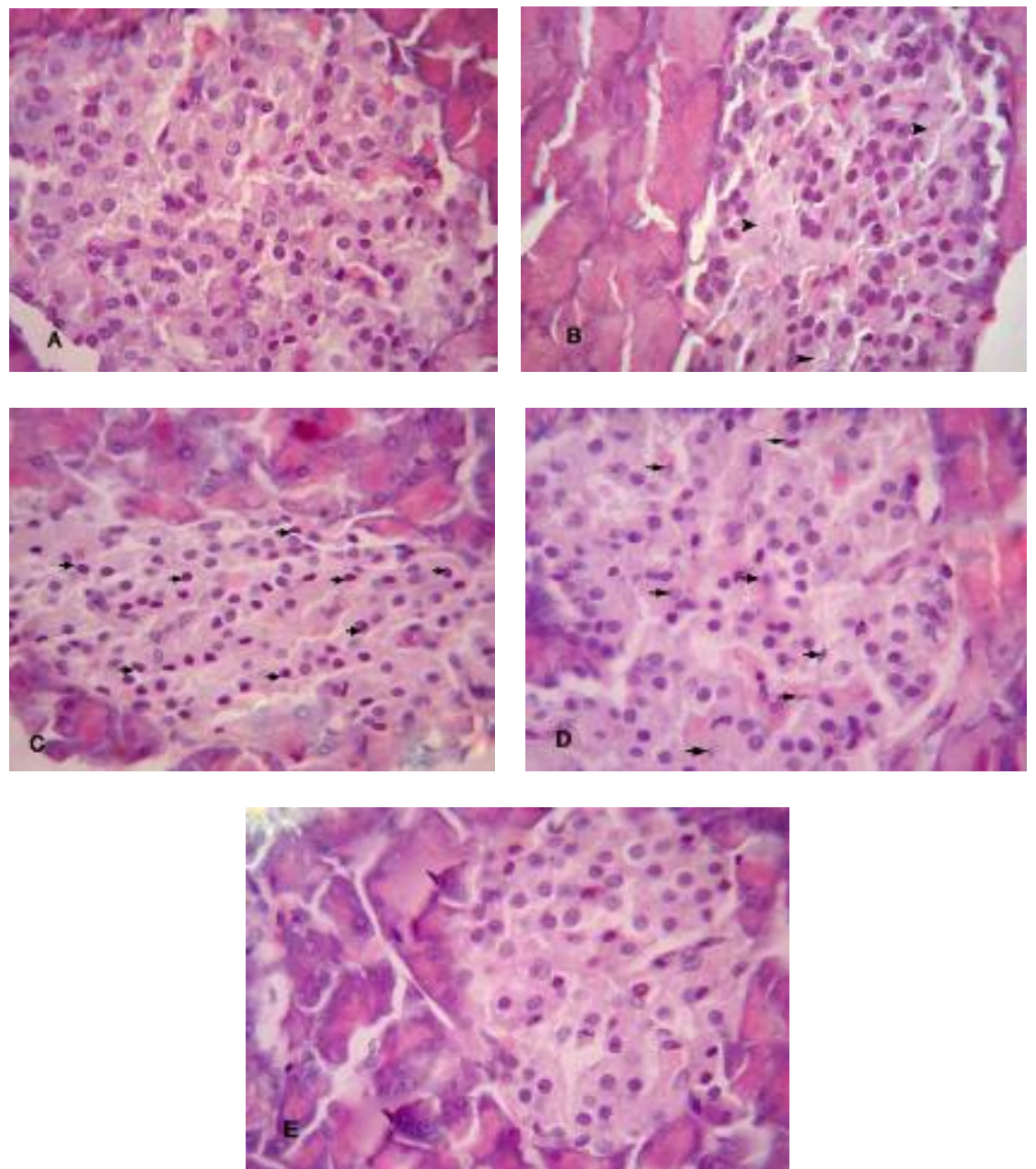

Figure (4): (A) Paraffin sections of control pancreatic tissue illustrating normal healthy islets of Langerhans embedded among the pancreatic acini. (B) Marked reduction in the size of islets of Langerhans of diabetic pancreatic tissue with extensive degeneration of beta cells in Islets (arrows). (C) Islets of Langerhans of diabetic pancreatic tissue illustrating prominent infiltration of lymphocytes (insulitis) within and around the islets (arrows). (D) Diabetic pancreatic tissue show large amount of apoptotic cells in many areas (arrows) with concomitant infiltration of lymphocytes (insulitis) within and around the islets. (E) Islets of Langerhans of diabetic pancreatic tissue receiving antioxidants for two months showing significant reduction in both apoptotic cells and lymphocyte infiltration (insulitis). Degeneration of beta cells in Islets is not found (H \& E original magnification X 400). 

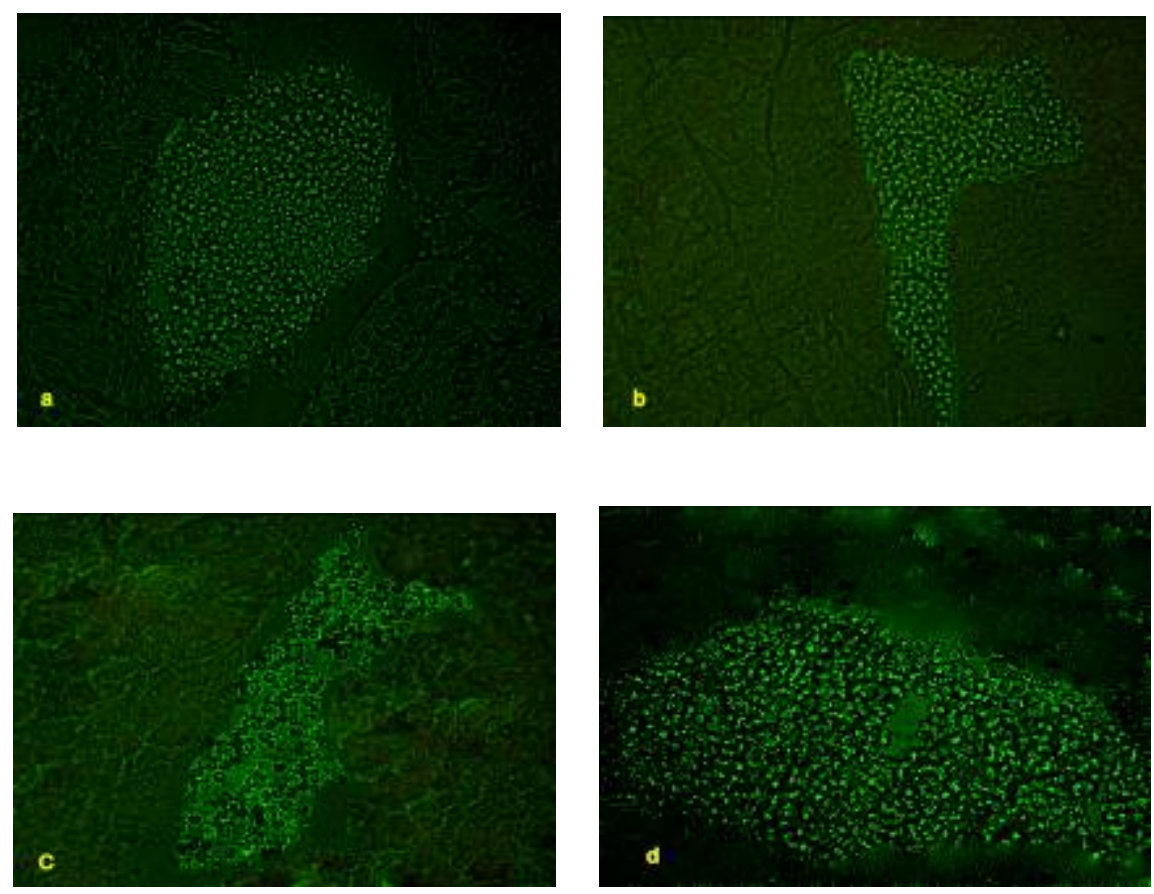

Figure (5): (a) Immunohistochemical staining sections of control pancreatic tissue showed the p65 subunit of the transcription factor NF-к $\beta$ complex was in the cytoplasm of $\beta$ - cells as a bright green color. No intracellular movement of NF-к $\beta$ is apparent. (b) Sections of diabetic pancreatic tissue demonstrated nuclear translocation of p65 subunit of NF-к $\beta$ complex from cytosol to nuclei and appeared as a bright green spots in the islets. (c) Apoptotic cells of diabetic pancreatic tissue appeared as distinct rounded cells with condensed bright green nuclei. (d) Sections of diabetic pancreatic tissue receiving antioxidants for two months showing that antioxidants supplementation inhibited transcription factor NF-к $\beta$ activation and blocked nuclear translocation of the p65 subunit of transcription factor NF-к $\beta$ into nuclei, treated islets cells are appeared as control islets cells (Immunofluorescence staining original magnification X 100). 


\section{DISCUSSION}

The results of the present study indicated profound destruction of the $\beta$-cells of the islets of Langerhans in the pancreas, resulting in the inability to produce insulin. Without insulin, severe disturbance in glucose metabolism results, causing intracellular starvation and a dramatic elevation in blood glucose levels or hyperglycemia ${ }^{(16)}$.

The incidence of experimental type 1 diabetes causing hyperglycemia due to the toxicity of cyclophosphamide which induces regulatory $\mathrm{T}$-cells specific for antigens expressed in $\beta$-cells cause pancreatic islet cell infiltration with subsequent destruction of $\beta$-cells of islets of Langerhans ${ }^{(17)}$.

Hyperglycemia in type 1 diabetes probably results from a long-term negative balance between immunemediated $\beta$-cell damage and $\beta$-cell repair/regeneration.

Once macrophages and T-cells have been attracted to the islets and activated, they secrete soluble mediators such as nitric oxide (NO), cytokines and oxygen free radicals, which probably induce apoptosis, the main mode of $\beta$ cell death in the development of type 1 diabetes $^{(\mathbf{1 8})}$.

The pathogenesis of type 1 diabetes is characterized by an inflammatory reaction that is caused, at least in part, by inflammatory cytokines produced by infiltrating $\mathrm{T}$ lymphocytes and/or macrophages in and around islets. Inflammatory cytokines, such as tumor necrosis factor (TNF- $\alpha$ ) produced by these cells, initiate a variety of signal cascades in $\beta$-cells that lead to $\beta$-cell dysfunction and destruction. The generation of oxygen free radicals is well known to be one of the main mechanisms of such cytokine mediated $\beta$-cell damage ${ }^{(\mathbf{1 9})}$.

Although apoptosis of pancreatic $\beta$-cells is a critical step in the development of type 1 diabetes, it has not yet been clearly elucidated which molecules are the real effectors of pancreatic $\beta$-cell death. Previous studies suggested that TNF- $\alpha$ is responsible for the final apoptosis of pancreatic $\beta$-cells ${ }^{(4)}$.

The pancreatic islets are known to have much lower antioxidant defense enzymes than other tissues such as liver; thus, they are highly susceptible to oxidative damage. The specificity of NF-к $\beta$ activation in the pancreas may be the key factor in increased free radical production. Previous studies have shown that the antioxidants can effectively and specifically inhibit pancreatic NF-к $\beta$ activation and is able to attenuate the severity of the disease ${ }^{(8)}$.

The present study indicated high concentration of the proinflammatory cytokine (TNF- $\alpha)$ and the nuclear transcription factor $(\mathrm{NF}-\kappa \beta)$ of diabetic rats because of hyperglycemia and oxidative stress resulting activation of NF-к $\beta$ which binds to nuclear DNA and modulates the expression of several genes for adhesion molecules, such as selectins, intercellular adhesion molecule 1, and vascular adhesion molecule 1 , and upregulates the production of various proinflammatory cytokines such as tumor necrosis factor (TNF- $\alpha)$, and inducible nitric oxide synthase (iNOS). These results are in 
accordance with those of Tabatabaie et al. ${ }^{\text {(3) }}$.

Nuclear transcription factor- $\kappa \beta$ $(\mathrm{NF}-\mathrm{\kappa} \beta)$ is a transcription factor that can be activated by a variety of stresses such as oxidants, free radicals and proinflammatory cytokines. NF$\kappa \beta$ is usually stored in the cytosol in its inactive form bound to the inhibitory protein unit iк $\beta$. Activation of NF- $\beta$ in response to extracellular stimuli involves the release of iк $\beta$, resulting in a rapid translocation of NF- $\kappa \beta$ to the nucleus to initiate transcription by high affinity binding to regulatory $\kappa \beta$ motifs in target genes. The $\kappa \beta$ motif has been identified in the promoter region of a number of genes involved in the initiation and progression of human preterm and term labor, including components of the phospholipids metabolizing pathway such as, phospholipase $\mathrm{A}_{2}$, proinflammatory cytokines TNF- $\alpha$ and proteases matrix metalloproteinase- 9 and urokinasetype plasminogen activator ${ }^{(\mathbf{2 0})}$.

Enzymes that catalyze the ubiquitination and degradation of phospho-ік $\beta$ are constitutively active, indicating that the principal regulatory step in the activation of NF-к $\beta$ is Ік $\beta$ phosphorylation. The previous discoveries and characterization of these enzymes provide a unique opportunity to investigate and potentially identify novel molecular targets of antioxidant action, which have the demonstrated ability to block activation of the NF-к $\beta$ pathway ${ }^{(6)}$.

The supplementation with antioxidants (NAC, LA, vitamin E and vitamin $\mathrm{C}$ ) of experimental diabetic rats in this study, ameliorate hyperglycemia, decreasing the cytokine TNF- $\alpha$ concentration and inhibit the activity of NF-к $\beta$.

$\mathrm{N}$-Acetyl cysteine is derived from the thiol-containing amino acid, cysteine. It has antioxidant properties that inhibits the induction of insulin resistance, increases intracellular glutathione concentrations (an endogenous reducing agent) and/or acts directly as a free radical scavenger ${ }^{(20)}$.

However, NAC provides cysteine for and promotes the synthesis of GSH. GSH has been found to have cellular functions unrelated to its antioxidant activity, such as serving as a cofactor in the glyoxalase-catalyzed metabolism of methylglyoxal ${ }^{(21)}$. GSH is the substrate of GSH-transferase and GSH-peroxidase, increases in tissue GSH may alter the consequences of hyperglycemia as well as reduce the oxidative damage of target tissue. GSH also protects sulfhydryl groups from oxidation. GSH is not only an effective antioxidant, but also modulates cellular metabolism and gene expression by affecting cellular thiol redox status. Intracellular redox status appears to be a critical determinant of NF-к $\beta$ activation. Hence, if ROSinduced NF-к $\beta$ activation modulates and amplifies the processes leading to $\beta$-cell death, inhibition of NF-к $\beta$ activation by GSH should prevent this damage and the development of type 1 diabetes $^{(8)}$.

On the other hand, NAC scavenges hydrogen peroxide, which is produced in the cytoplasm and probably the nuclei of cells as a direct consequence of the glycation reaction. Once produced, hydrogen peroxide has a relatively long lifespan and can 
be transferred anywhere by penetrating nuclear and plasma membranes. Indeed, hydrogen peroxide is known to mediate the glycation-dependent degradation of several proteins and is widely involved in the damage of various tissues in diabetes. Therefore, it seems reasonable that NAC, which is known to decrease the intracellular hydrogen peroxide level in $\beta$-cells, was effective for preventing $\beta$-cell damage ${ }^{(22)}$.

The treatment with NAC in our study inhibited the cytokine TNF- $\alpha$ and many other enzyme activities. Furthermore, this inhibition was associated with a concomitant suppression of NF-к $\beta$ DNA-binding activity. Similarly, others have demonstrated that NAC inhibits the expression, release, and/or activity of proinflammatory cytokines and through suppression of NF-к $\beta$ activation in a number of other systems $^{(20)}$.

Lipoic acid (LA) is one of the most potent natural antioxidants. Many lines of evidence have shown that both LA and its reduced form, dihydrolipoic acid (DHLA), have multifunctional antioxidant activities with the following characteristics. First, LA/DHLA is amphiphilic and readily cross the blood-brain barrier and cell membranes. Second, LA/DHLA possesses metal-chelating activity. Third, LA is reduced to DHLA by several antioxidant enzymes that are expressed constitutively in most types of cells. In addition, because of its strong negative redox potential, DHLA can recycle other antioxidants, such as vitamin $\mathrm{C}$, vitamin $\mathrm{E}$, glutathione. Also, dihydrolipoic acid increases intracellular levels of coenzyme Q10, $\mathrm{NADPH}$, and NADH via increased glutathione availability ${ }^{(23)}$.

LA also acts as a scavenger of several free radicals, including hydroxyl radicals, hypochlorous acid, and singlet oxygen in both lipid and aqueous phase, chelates transition metals, and prevents membrane lipid peroxidation and protein damage via interactions with vitamin $\mathrm{C}$ and glutathione $^{(9)}$. Previous investigations suggest that supplements of LA reduce oxidative stress in both diabetic patients and animal models and that it is particularly suitable for prevention and/or treatment of diabetic complications ${ }^{(\mathbf{2 4})}$.

A potential explanation for the protective effects of LA on $\mathrm{H}_{2} \mathrm{O}_{2-}$ induced insulin resistance may be related to its ability to preserve the intracellular redox balance, acting either directly or through other endogenous antioxidants, such as glutathione. The limiting factor in glutathione synthesis is the bioavailability of intracellular cysteine. LA and NAC generate intracellular cysteine from extracellular cystine and thus maintain reduced glutathione levels ${ }^{(25)}$.

Treatment with LA reduces markers of oxidative stress in plasma of patients with diabetes mellitus and poor glycemic control. There is evidence in both human and experimental diabetes mellitus that administration of LA ameliorates diabetic neuropathy. Oral LA administration associated with a reduction in serum malondialdehyde and also associated with an increase in the glutathione content of this tissue, suggesting that this intracellular 
antioxidant moiety may participate in the protection of both the nerve and the kidney from injury in diabetes mellitus ${ }^{(9)}$

Vitamin $E$ is an important antioxidant. It acts as a free radical scavenger to prevent the byproducts of chemical-cell interaction to cause cell damage. Free radicals are likely responsible for all or most of the degenerative diseases ${ }^{(26)}$. It also plays some role in the body's ability to process glucose, so it may eventually prove to be helpful in the prevention and treatment of diabetes ${ }^{(27)}$.

Vitamin E has anti-inflammatory effects. It was shown previously that short-term supplementations with high doses of vitamin $\mathrm{E}$ decrease the in vitro production of cytokines such as tumor necrosis factor (TNF- $\alpha$ ) by peripheral mononuclear cells and reduce levels of $\mathrm{C}$ reactive protein $(\mathrm{CRP})^{(28)}$.

$\alpha$-tocopherol is the major form of vitamin $\mathrm{E}$ in human plasma, it is important lipid-soluble antioxidant, and it protects membranes from oxidation by reacting with lipid radicals produced in the lipid peroxidation chain reaction. This removes the free radical intermediates and prevents the propagation reaction from continuing. This reaction produces oxidized $\alpha$-tocopheroxyl radicals that can be recycled back to the active reduced form through reduction by other antioxidants ${ }^{(29)}$.

Vitamin $\mathrm{C}$ or ascorbic acid is a monosaccharide antioxidant. It is a vitamin and it must be obtained from the $\operatorname{diet}^{\left({ }^{30)}\right.}$. Most other animals are able to produce vitamin $\mathrm{C}$ in their bodies and do not require it in their $\operatorname{diets}^{(31)}$. In cells, it is maintained in its reduced form by reaction with glutathione, which can be catalyzed by protein disulfide isomerase and glutaredoxins ${ }^{(32)}$. Ascorbic acid is a reducing agent and can reduce and thereby neutralize reactive oxygen species such as hydrogen peroxide ${ }^{(33)}$.

Vitamin $\mathrm{C}$ is a potent antioxidant with increasingly diverse uses in health promotion and disease prevention. It reduces cellular DNA damage that is the vital first step in cancer initiation and also reduces the inflammatory changes that allow a malignant cell to grow into a dangerous tumor. Vitamin $\mathrm{C}$ can benefit in preventing endothelial dysfunction and altering lipid profiles and coagulation factors so preventing blood vessel changes that can lead to strokes and other vascular catastrophes. Vitamin C supplements may help to lower blood glucose levels in diabetics with additional beneficial reductions in low-density lipoprotein (LDL) and plasma free radicals ${ }^{(34)}$.

Histopathological studies of islets of Langerhans in diabetic rats showed prominent destruction of islets epithelial cells, which were seen as disorganized and dyshesive cells of variable size having evident intercellular spaces and large dense hyperchromic nuclei. Marked reduction in the size of islets of Langerhans when compared to control ones, due to extensive degeneration of beta cells in islets, with cellular spacing and disorganization attaining a dyshesive pattern ${ }^{(35)}$. Some islets showed large amount of apoptotic cells in many areas, but others showed absence of beta cells, due to sever cell death. Obvious infiltration of 
lymphocytes (insulitis) within and around the Islets is found ${ }^{(\mathbf{1 6 )}}$. .

Immunofluorescence staining showed activation of transcription factor NF-к $\beta$ and nuclear translocation of the p65 subunit from cytosol to nuclei which become visible as a bright green spots. Apoptotic cells appeared as distinct rounded cells with up normal bright green nuclei, due to nuclear condensation/ fragmentation of staining ${ }^{(4)}$.

Histopathological studies of islets of Langerhans of diabetic pancreatic tissue receiving antioxidants showed relative restoration of the epithelial cells cohesiveness with minimal intercellular spaces. Some islets showed evident regeneration and crowding of $\beta$ - epithelial cells reaching normal appearance. Significant reduction in both apoptotic cells and the amount of infiltrating lymphocytes (insulitis) are appeared, when compared with diabetic tissue $^{(22)}$.

Immunofluorescence staining showed that antioxidants supplementation inhibited transcription factor NF-к $\beta$ activation and blocked nuclear translocation of the p65 subunit of transcription factor NF-к $\beta$ into nuclei, treated islets cells are appeared as control islets cells. These findings indicate that antioxidants protect $\beta$-cells of diabetic rats from injury ${ }^{(36)}$.

In conclusions, based on these observations, we can conclude the sequence of events that lead to the development of diabetes. Early initiation events begin with increased free radical production and lipid peroxidation process through the toxicity of hyperglycemia, which in turn activates NF-к $\beta$. This activation of NF-к $\beta$ both initiates and amplifies inflammatory responses through upregulation of cytokines and proinflammatory proteins such as iNOS. This amplification cascades results of increased free radical production and eventually leads to the development of IDDM, then the antioxidants (NAC, LA, vitamin $\mathrm{E}$ and vitamin C) can inhibit these processes that should inhibit the disease. Thus, the use of these antioxidants may be very important in preventing activation of these pathways. Moreover, identification of the molecular basis for the protection afforded by a variety of antioxidants against oxidative-induced damage might lead to the discovery of pharmacological targets for novel therapies to prevent, reverse, or delay the onset of the resultant pathologies.

\section{REFERENCES}

1. Hayashi, T. and Faustman, D.L. (2003): Role of defective apoptosis in type 1 diabetes and other autoimmune diseases. Recent Prog. Horm.Res., 58: 131153.

2. Mellado-Gil1, J. M. and Aguilar-Diosdado1, M. (2005): Assay for high glucose-mediated Islet cell sensitization to apoptosis induced by streptozotocin and cytokines. Biol. Proceed. Online 7(1): 162171.

3. Tabatabaie, T.; VasquezWeldon, A.; Moore, D. R. and Kotake, Y. (2003): Free radicals and the pathogenesis of type 1 diabetes $\beta$-cell cytokine-mediated 
free radical generation via cyclooxygenase-2. Diabetes, 52:1994-1999.

4. Chang, I.; Kim, S.; Kim, J.Y.; Cho, N.; Kim, Y.; Kim, H.S.; Lee, M.; Kim, K. and Lee, M. (2003): Nuclear Factor $\kappa \beta$ protects pancreatic $\beta$-cells from tumor necrosis factor- $\alpha$ mediated apoptosis. Diabetes, 52:11691175.

5. Gillespie, K. M. (2006): Type 1 diabetes: pathogenesis and prevention. CMAJ., 175(2):165170.

6. Evans, J. L.; Goldfine, I. D.; Maddux, B. A. and Grodsky, G. M. (2002): Oxidative stress and stress-activated Signaling pathways: A unifying hypothesis of type 2 diabetes. Endocrine Reviews, 23: 599-622.

7. Apostolou, I.; Hao, Z.; Rajewsky, K.and Boehmer, $\mathbf{H}$. V. (2003): Effective destruction of fas-deficient insulin-producing $\beta$-cells in type 1 diabetes. J. Exp. Med., 198(7):1103-1106.

8. Ho, E.; Chen, G. and Bray, T. M. (1999): Supplementation of $\mathrm{N}$-acetyl cysteine inhibits NF- $\mathrm{\beta}$ activation and protects against alloxan-induced diabetes in CD-1 mice. FASEB J., 13:1845-1854.

9. Melhem, M. F.; Craven, P. A. and Derubertis, F. R. (2001): Effects of dietary supplementation of $\alpha$-lipoic acid on early glomerular injury in diabetes mellitus. J. Am. Soc. Nephrol., 12: 124-133.

10. Barham, D. and Trinder, $P$. (1972): An improved color reagent for the determination of blood glucose by the oxidase system. Analyst 97(151): 142145.

11. New, D. R.; Maggirwar, S. B.; Epstein, L. G.; Dewhurst, S. and Gelbard, H. A. (1998): HIV-1 Tat induces neuronal death via tumor necrosis factor- $\alpha$ and activation of non-N-methyl-Daspartate receptors by a NF $k B$ independent mechanism. J. Biol. Chem., 273(28): 17852-17858.

12. Davis, J. N. and Sarkar, F. S. (2001): Soy isoflavone supplementation in healthy men prevents NF-k $\beta$ activation by TNF- $\alpha$ in blood lymphocytes. Free Rad. Bio. Med., 11: 12931302.

13. Harris, N. S. (1992): Anatomy and physiology. (5ed), St. Houis: 65.

14. Nadji, M. and Morales, A. R. (1983): Immunoperoxidase, part 1: the techniques and its pitfall. Lab. Med., 14:767-770.

15. Pedraza, M.A.; Mason, D.; Doslu, F.A.; Marsh, R.A. and Boblett, J.P. (1984): Immunoperoxidase methods with plastic embedded materials. Lab. Med., 15(2):113-115.

16. HO, E.; Quan, N.; Tsai, Y. H.; Lai, W. and Bray, T. M. (2001): Dietary zinc supplementation inhibits NF-к $\beta$ activation and protects against chemically induced diabetes in CD1 mice. Exp. Biol. Med., 226:103-111.

17. Quintana, F. J.; Hagedorn, P. H.; Elizur, G.; Yifat Merbl, Y.; Domany, E. and Cohen, I. R. (2004): Functional immunomics: Microarray analysis of $\operatorname{IgG}$ autoantibody repertoires predicts the future response of mice to 
induced diabetes. PNAS, 101(2): 14615-14621.

18. Kharroubi, I.; Ladrie re, L.; Cardozo, A. K.; Dogusan, Z.; Cnop, M. and Eizirik, D. L. (2004): Free fatty acids and cytokines induce pancreatic $\beta$-cell apoptosis by different mechanisms: Role of nuclear factor- $\beta$ and endoplasmic reticulum stress. Endocrinology, 145: 5087-5096.

19. Matsuda, T.; Ferreri, K.; Todorov, I.; Kuroda, Y.; Smith, C. V.; Kandeel, F. and Mullen, Y. (2005): Silymarin protects pancreatic $\beta$-cells against cytokine- mediated toxicity: Implication of c-Jun NH2terminal kinase and Janus kinase/signal transducer and activator of transcription pathways. Endocrinology, 146: 175-185

20. Lappas, M.; Permezel, M. and Rice, G. E. (2003): N-AcetylCysteine inhibits phospholipid metabolism, proinflammatory cytokine release, protease activity, and nuclear factor-к $\beta$ deoxyribonucleic acid-binding activity in human fetal membranes in vitro. J. Clin. Endocrinol. Metab., 88: 17231729.

21. Haber, C. A.; Lam, T. K. T.; Yu, Z. ; Gupta, N. ; Goh, T. ; Bogdanovic, E. ; Giacca, A.. and Fantus, I. G. (2003): Nacetyl cysteine and taurine prevent hyperglycemia-induced insulin resistance in vivo: possible role of oxidative stress. Am. J. Physiol. Endocrinol. Metab., 285: E744-E753.
22. Kaneto, H. ; Kajimoto, Y. ; Miyagawa, J. ; Matsuoka, T. ; Fujitani, Y. ; Umayahara, Y. ; Hanafusa, T. ; Matsuzawa, Y. ; Yamasaki, Y. and Hori, $M$. (1999): Beneficial effects of antioxidants in diabetes possible protection of pancreatic $\beta$-cells against glucose toxicity. Diabetes, 48:2398-2406.

23. Yi, X. and Maeda, N. (2005): Endogenous production of lipoic acid is essential for mouse development. Mol. cell. Biol., 25(18): 8387-8392.

24. Sola, S.; Mir, M. Q. S.; Cheema, F. A.; KhanMerchant, N.; Menon, R. G. Parthasarathy, S. and Khan, B. V. (2005): Irbesartan and lipoic acid improve endothelial function and reduce markers of inflammation in the metabolic syndrome results of the irbesartan and lipoic acid in endothelial dysfunction (ISLAND) study. Circulation, 111:343-348.

25. Maddux, B.A.; See, W.; Lawrence, J.C.; Jr.; Amy L. Goldfine, Goldfine, I. D. and Joseph L. Evans, J. L. (2001): Protection against oxidative stress-induced insulin resistance in rat L6 muscle cells by micromolar concentrations of $\alpha$ Lipoic acid. Diabetes 50:404410.

26. Meydani, S.N.; Wu, D.; Santos, M. S. and Hayek, M.G. (1995): Antioxidants and immune response in aged persons: Overview of present evidence. Am. J. Clin. Nutr., 62(6): 1462S$1476 \mathrm{~S}$. 
27. Azzi, A.; Breyer, I.; Feher, M.; Pastori, M.; Ricciarelli, R.; Spycher, S.; Staffieri, M.; Stocker, A.; Zimmer, S. and Zingg, J. (2000): Specific cellular responses to $\alpha$ tocopherol. J. Nutr., 130:16491652.

28. Bruunsgaard, H.; Poulsen, H.E.; Pedersen, B. K.; Nyysso"nen, K.; Kaikkonen, J. and Salonen, J.T. (2003): Longterm combined supplementations with $\alpha$-tocopherol and vitamin $\mathrm{C}$ have no detectable antiinflammatory effects in healthy men. J. Nutr., 133:1170-1173.

29. Traber, M. G. and Leonard, S. W. (2001): The Alpha-tocopherol Transfer Protein and Vitamin E Adequacy. The Linus Pauling Institute, Micronutrient Information Center. Oregon State University 1- 5.

30. Smirnoff, N. (2001): L-ascorbic acid biosynthesis. Vitam. Horm., 61: 241- 66

31. Linster, C. L. and Van Schaftingen, E. (2007): Vitamin C. biosynthesis, recycling and degradation in mammals. FEBS. J., 274(1): 1-22.

32. Meister, A. (1994): Glutathioneascorbic acid antioxidant system in animals. J. Biol. Chem., 269

(13): 9397-400.

33. Padayatty, S.; Katz, A.; Wang, Y.; Eck, P.; Kwon, O.; Lee, J.;

Chen, S.; $\quad$ Corpe, C;

Dutta, A.; Dutta, S. and Levine, M. (2003): Vitamin $\mathrm{C}$ as an antioxidant: evaluation of its role in disease prevention. J. Am. Coll. Nutr., 22 (1): $18-35$.

34. Afkhami-Ardekani, M. and Shojaoddiny-Ardekani, A. (2007): Effect of vitamin $\mathrm{C}$ on blood glucose, serum lipids \& serum insulin in type 2 diabetes patients. Indian J. Med. Res., 126: 471-474.

35. Melanitou, E.; Joly, F.; Mark Lathrop, M.; Boitard, C. and Avner, P. (1998): Evidence for the presence of insulindependent diabetes-associated alleles on the distal part of mouse chromosome 6. Genome Res., 8: 608-620.

36. Chen, H.; Li, X. and Epstein, P.N. (2005): MnSOD and catalase transgenes demonstrate that protection of islets from oxidative stress does not alter cytokine toxicity. Diabetes, 54:1437-1446. 


\section{دورالسيتوكينات فى الجرذان المصابة بمرض البوال السكرى}

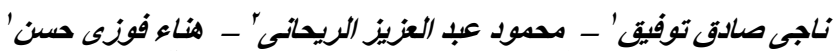

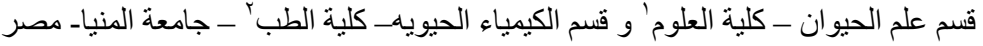

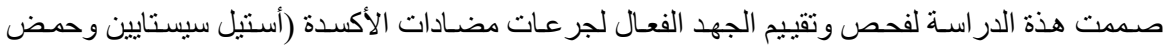

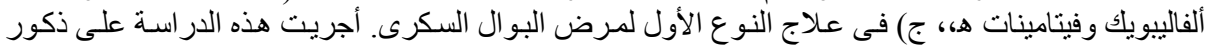

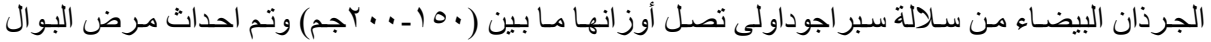

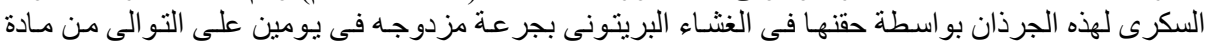

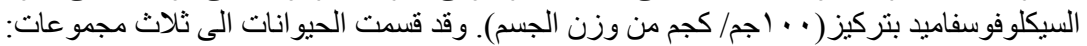

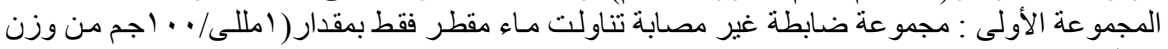
الجسم) لمدة شهرين. المجموعة الثانية : مجمو عة ضـابطة مصابة بالبو ال السكرى تناولت ماء مقطر فقط بمقدار ( مللى/ . . اجم من وزن الجسم) لمدة شهرين.

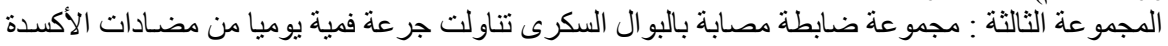

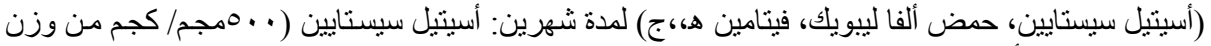

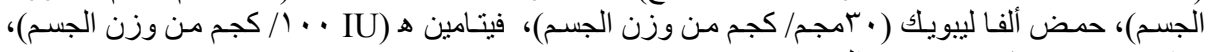

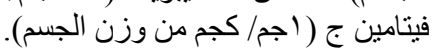

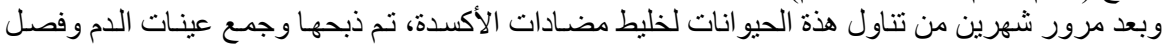

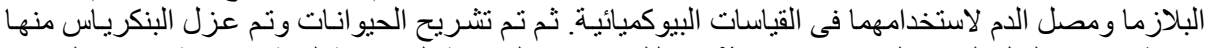

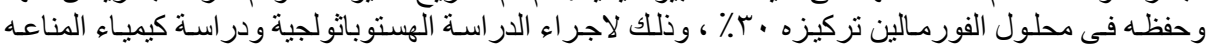

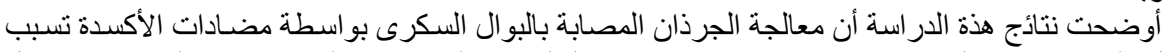

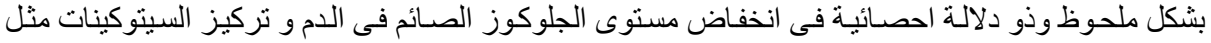

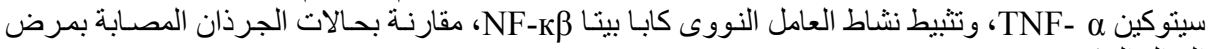

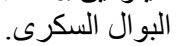

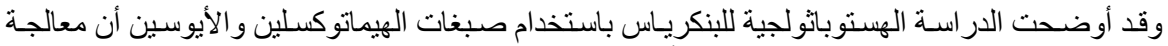

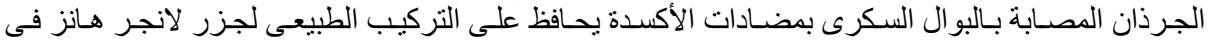

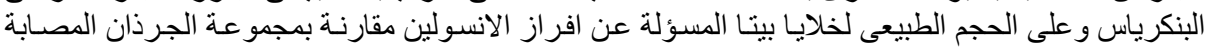
بالبو ال السكرى.

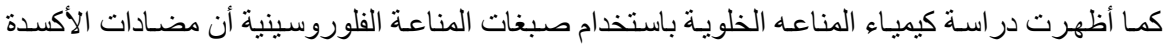

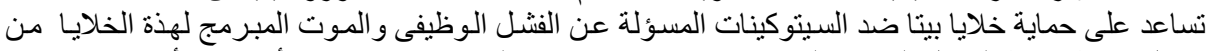

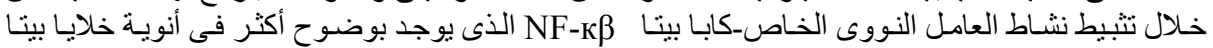

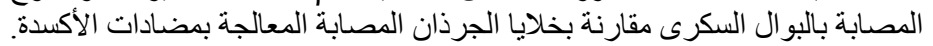

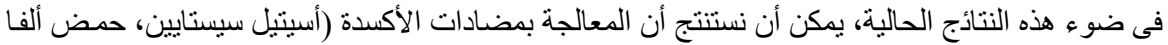

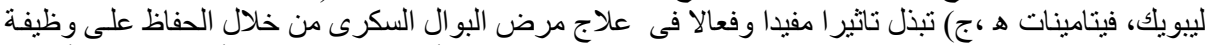

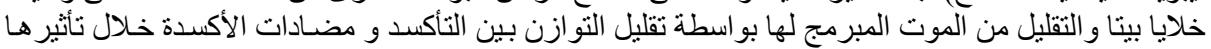
على تنظيف الثقوق الحرة. 
